\title{
Clinical symptoms, endoscopic imaging and stroboscopic imaging in patients with laryngeal fungal infection : An evaluation in 48 patients
}

\author{
Ngo Thi Linh Trang ${ }^{1, *}$, Dao Dinh Thi ${ }^{2}$, Nguyen Tuan Son ${ }^{1}$
}

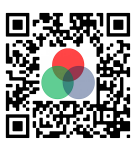

Use your smartphone to scan this QR code and download this article

\begin{abstract}
Introduction: Aspergillus fumigatus and Candida albicans are the most common pathogenic fungi found in Vietnam. Fungal laryngitis has yet to be thoroughly investigated due to the rarity of the disease. This study aimed to describe the clinical, endoscopic and stroboscopic imaging characteristics among patients with fungal laryngitis. Methods: A cross-sectional study was performed on 48 patients diagnosed with fungal laryngitis at the Endoscopy Department of the National EarNose-Throat Hospital of Vietnam from August 2019 to March 2020. Clinical, endoscopic and stroboscopic imaging characteristics among patients with fungal laryngitis were reported. Results: The rate of fungal laryngitis was higher in men compared to women (men/women ratio: 2.2/1). All patients had dysphonia (100\%), while other symptoms included coughing (64.6\%) and foreign body sensation (50\%). In laryngeal endoscopy, fungal pseudo-membrane was thick with white layer (56.3\%) on the vocal cords (100\%). In laryngeal stroboscopy, less than half of patients had mucosal wave formation (47.9\%). The success rate of fungal culture identification was not high (41.7\%), with Aspergillus fumigatus as the main pathogenic fungus (90\%). Conclusions: Patients with fungal laryngitis in our setting developed prolonged dysphonia. By using endoscopic imaging and stroboscopic imaging, layers of fungal pseudo-membrane on the vocal cords could be observed and extracted for diagnosis.
\end{abstract}

Key words: fungal laryngitis, dysphonia, endoscopic imaging, stroboscopic imaging, fungal identification

\section{INTRODUCTION}

Pharmacy, Vietnam National University,

Hanoi, Hanoi, Vietnam

${ }^{2}$ National Hospital of

Otorhinolaryngology, Hanoi, Vietnam

Correspondence

Ngo Thi Linh Trang, VNU School of Medicine and Pharmacy, Vietnam National University, Hanoi, Hanoi, Vietnam

Email: linhtrang.ngth@gmail.com

History

- Received: May 21, 2020

- Accepted: Sep 18, 2020

- Published: Sep 30, 2020

DOI : 10.15419/bmrat.v7i9.631

\section{Check for updates}

\section{Copyright}

(c) Biomedpress. This is an openaccess article distributed under the terms of the Creative Commons Attribution 4.0 International license.

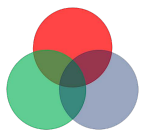

BioMedPress The Open Access Publisher
Laryngeal fungal infection, or fungal laryngitis, refers to the inflammation of the larynx caused by fungi, an organism group which is often found in the environment $^{1,2}$. HIV/AIDS, tuberculosis, chronic obstructive pulmonary disease, and cancer are the major drivers of fungal infections ${ }^{3}$. Fungal laryngitis results in the presentation of prolonged hoarseness of the voice (dysphonia), coughing, and foreign body sensation ${ }^{4}$.

Aspergillus fumigatus and Candida albicans are the most common pathogenic fungi found in Viet $\mathrm{Nam}^{5,6}$. Fungal laryngitis has yet to be thoroughly researched due to the rarity of the disease. Moreover, its generic symptoms are usually mistaken for other disorders of the larynx, which may lead to misdiagnosis or delayed diagnosis of chronic laryngitis $(30.8 \%)$ and cancer $(28.9 \%)$, causing inadequate, prolonged treatment ${ }^{5}$. Recent applications of new diagnostic methods, such as endoscopic imaging, stroboscopic imaging, and fungal identification, have proven their efficiency in diagnosing fungal laryngitis. Further understanding of clinical and paraclinical characteristics of fungal laryngitis is required to improve the accuracy of diagnosis. This study aimed to describe the clinical symptoms, as well as endoscopic and stroboscopic imaging characteristics of patients with fungal laryngitis.

\section{MATERIALS - METHODS}

\section{Study design}

This cross-sectional study enrolled 48 patients diagnosed with fungal laryngitis at the Endoscopy Department of the National Ear-Nose-Throat Hospital of Vietnam, from August 2019 to March 2020. This study was reviewed and approved by the Institutional Review Board of the School of Medicine and Pharmacy, Vietnam National University, Hanoi, Vietnam (Code: 750/QD-KYD). Patients were included if they had clear fungal laryngitis diagnoses using direct microscopy, with endoscopic imaging, and with stroboscopic imaging test results. Patients were excluded if they: 1) had unclear fungal laryngitis diagnoses, or were diagnosed with fungal laryngitis without endoscopic imaging or stroboscopic imaging, and 2) refused to participate in the study. 


\section{Data sources and measurements}

In this study, we collected data regarding general demographic characteristics (age, gender, living place (urban/rural), and occupation (agricultural labor and office)), patients' medical history of pneumonia, hepatitis $\mathrm{B}$, and smoking habit. For clinical symptoms, we collected information about symptoms such as dysphonia, coughing, foreign body sensation, fever, and dyspnea. We categorized the level of severity of dysphonia into three levels including: mild, moderate, and severe. Moreover, we identified aphonia and its duration among patients, which was divided into 3 categories: less than 1 month, 1 to 3 months, and more than 3 months.

In terms of paraclinical characteristics, we collected data about patients' endoscopic imaging, stroboscopic imaging, and fungal identification results. For endoscopic imaging, we focused on the pseudomembrane characteristics including its amount found in endoscopy (thick, thin, or patchy), its placement on the vocal cords and surrounding areas, and the epithelium layer characteristics under the pseudomembrane (inflamed, swollen, or ulcerated). For stroboscopic imaging, we focused on the general characteristics of the vocal cords: the adduction - abduction movement, the closing phase of the vocal cords, the mucosal wave appearance, and the laryngospasm. Mucosal wave characteristics were further described with regard to the frequency of the mucosal wave, the symmetry, the adduction posture, and the periodicity. Fungal identification result was coded as ${ }^{1}$ if the fungal culture was positive, or (0) otherwise. The pathogenic fungal species were divided into 2 categories: Aspergillus fumigatus and Candida albicans.

\section{Statistical analysis}

Data analysis were performed using SPSS Statistics 20. Univariate analysis was applied to present descriptive data in the form of frequency and percentages.

\section{RESULTS}

Of the 48 patients, the rate of fungal laryngitis in men $(68.8 \%)$ was two times higher than that in women (31.2\%). The majority of patients were aged 30 and older, and had labor work (54.2\%). Most of the patients lived in urban areas $(56.3 \%)$. The prevalence of pneumonia and hepatitis B were $10.4 \%$ and $14.6 \%$, respectively. There were $43.8 \%$ of patients who were current smokers.

Dysphonia was observed in all patients (100\%). The majority of patients had moderate dysphonia (50.0\%), followed by severe dysphonia (33.3\%) and mild dysphonia (16.7\%). Nearly half of them had dysphonia
Table 1: Dysphonia severity in studied patients

\begin{tabular}{|c|c|c|}
\hline Characteristics & $\begin{array}{c}\text { Number of } \\
\text { patients } \\
(\mathrm{n}=48)\end{array}$ & $\begin{array}{c}\text { Percentage } \\
(\%)\end{array}$ \\
\hline \multicolumn{3}{|l|}{ Dysphonia severity } \\
\hline Mild & 8 & 16.7 \\
\hline Moderate & 24 & 50.0 \\
\hline Severe & 16 & 33.3 \\
\hline \multicolumn{3}{|l|}{ Dysphonia duration } \\
\hline$<1$ month & 16 & 33.3 \\
\hline $1-3$ months & 11 & 22.9 \\
\hline$>3$ months & 21 & 43.8 \\
\hline \multicolumn{3}{|l|}{ Aphonia } \\
\hline Yes & 14 & 29.2 \\
\hline No & 34 & 70.8 \\
\hline \multicolumn{3}{|l|}{ Duration of Aphonia } \\
\hline$<1$ week & 13 & 92.8 \\
\hline$\geq 1$ week & 1 & 7.2 \\
\hline \multicolumn{3}{|l|}{ Other symptoms } \\
\hline Coughing & 31 & 64.6 \\
\hline $\begin{array}{l}\text { Foreign body sensa- } \\
\text { tion }\end{array}$ & 24 & 50.0 \\
\hline Dyspnea & 1 & 2.1 \\
\hline Fever & 1 & 2.1 \\
\hline
\end{tabular}

Table 2: Fungal pseudo-membrane characteristics

\begin{tabular}{lcc}
\hline Characteristics & $\begin{array}{c}\text { Number of } \\
\text { patients } \\
(\mathbf{n}=\mathbf{4 8})\end{array}$ & $\begin{array}{c}\text { Percentage } \\
(\%)\end{array}$ \\
$\begin{array}{l}\text { Pseudo-membrane } \\
\text { characteristics }\end{array}$ & 27 & 56.3 \\
Thick & 14 & 29.2 \\
$\begin{array}{l}\text { Thin } \\
\text { Patchy }\end{array}$ & 7 & 14.6 \\
$\begin{array}{l}\text { Tissue } \\
\text { under fungal pseudo } \\
\text { membrane }\end{array}$ & & \\
Inflamed & 30 & 62.5 \\
Swollen & 27 & 56.3 \\
Ulcerated & 11 & 22.9 \\
\hline
\end{tabular}



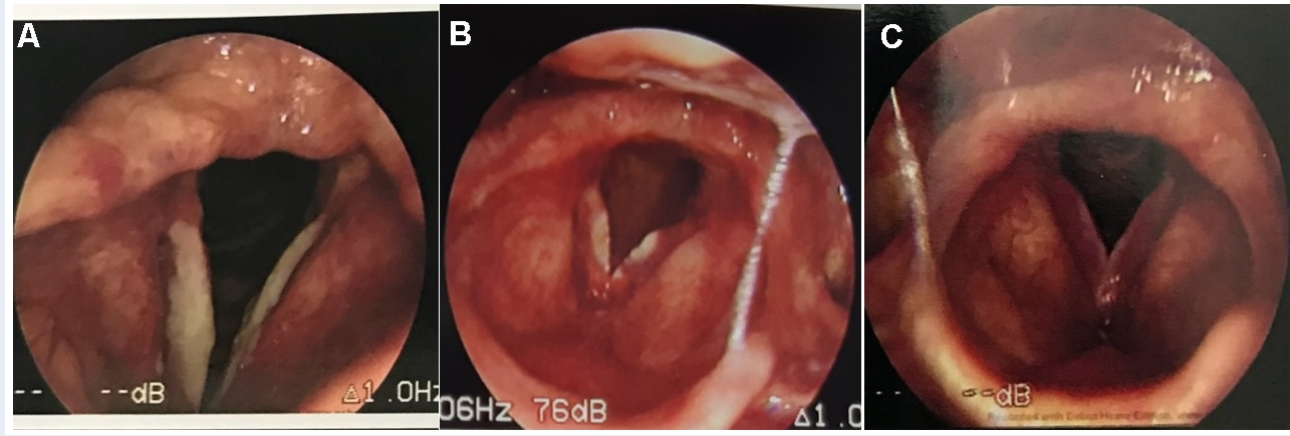

Figure 1: Fungal pseudo-membrane characteristics in studied patients. (A) A thick layer of the pseudomembrane; (B) A thin layer of the pseudo-membrane; (C) A patchy barely visible layer of the pseudo-membrane.

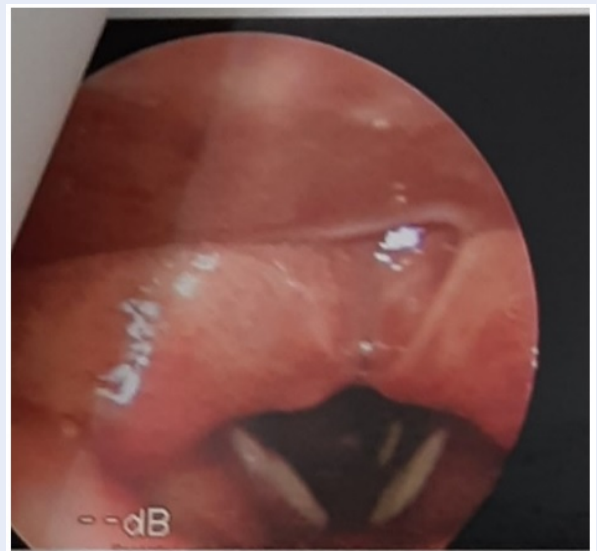

Figure 2: Fungal pseudo-membrane found on the subglottic. Fundal larynx spread to trachea.

for more than 3 months (43.8\%), followed by less than 1 month (33.3\%). There were $29.2 \%$ of patients who developed aphonia, and $92.8 \%$ of them visited hospitals within one week. Other notable symptoms included coughing (64.6\%) and foreign body sensation (50.0\%). Dyspnea and fever were rarely seen in the cases $(2.1 \%)$.

The fungal pseudo-membrane was often white, or whitish grey. The pseudo-membrane was more likely to be thick (56.3\%), covering all over the vocal cords. In some cases, the pseudo-membrane was a thin layer (29.2\%) or a patchy, barely visible layer (14.6\%), covering only a small part of the surface. Inflamed tissue layer was the most common form under the fungal pseudo-membrane $(62.5 \%)$, followed by swollen tissue $(56.3 \%)$ and ulcerated tissue (22.9\%).

All of the patients had pseudo-membrane on the vocal cords; most of them could be seen on both sides of the vocal cord (85.4\%). The pseudo-membrane could spread to the epithelium layer of the subglottic region (6.3\%) and even down to the trachea (2.1\%). The most common disorder detected in patients with fungal laryngitis was oropharyngitis (68.8\%). Rhinopharyngitis was rarely seen (4.2\%).

All patients had a normal adduct-abduct movement of the vocal cords $(100 \%)$. However, the mucosal wave formation was only found in less than half of the patients $(47.9 \%)$. Most of the patients did not have complete closure of vocal folds (87.5\%). There was only $6.3 \%$ of patients having laryngospasm in stroboscopic imaging. Most of the patients had decreased mucosal wave frequency (91.3\%). Moreover, patients with fungal laryngitis were more likely to have an asymmetrical wave (60.9\%). Patients with fungal laryngitis could also have non-isometric adduction posture of the vocal cords (47\%) and diverse periodicity (39.1\%).

Fungal identification tests had a low success rate (41.7\%). The majority of positive patients had Aspergillus fumigatus as their pathogenic fungi (90.0\%), while others had Candida albicans.

\section{DICUSSION}

This study contributed to the current knowledge of clinical and paraclinical characteristics of patients with fungal laryngitis in Vietnam. In this study, the main reason for hospital admission in our cases was dysphonia, which was consistent with other studies in Vietnam and worldwide ${ }^{3,5-7}$. Two-thirds of the patients suffered from mild to moderate levels of dysphonia, with barely noticeable changes in voice. In practice, dysphonia was sometimes only a symptom, which might not have significant influence on the patients' lives; thus, the patients would more likely to ignore, wait out, or self-treat the symptom with home remedies or generic medication until the dysphonia 
Table 3: General stroboscopic imaging characteristics in studied patients

\begin{tabular}{|c|c|c|}
\hline Characteristics & $\begin{array}{c}\text { Number of } \\
\text { patients } \\
(\mathrm{n}=48)\end{array}$ & $\begin{array}{c}\text { Percentage } \\
(\%)\end{array}$ \\
\hline \multicolumn{3}{|l|}{ Vocal cord } \\
\hline One side & 7 & 14.6 \\
\hline Both sides & 43 & 85.4 \\
\hline \multicolumn{3}{|c|}{$\begin{array}{l}\text { Vocal cord adduction - } \\
\text { abduction }\end{array}$} \\
\hline Normal & 48 & 100.0 \\
\hline Abnormal & 0 & 0.0 \\
\hline \multicolumn{3}{|l|}{ Mucosal wave } \\
\hline Yes & 23 & 47.9 \\
\hline No & 25 & 52.1 \\
\hline \multicolumn{3}{|c|}{$\begin{array}{l}\text { Closing phase of vocal } \\
\text { folds }\end{array}$} \\
\hline Incompletely closed & 42 & 87.5 \\
\hline Completely closed & 6 & 12.5 \\
\hline \multicolumn{3}{|l|}{ Laryngospasm } \\
\hline Yes & 3 & 6.3 \\
\hline No & 45 & 93.7 \\
\hline \multicolumn{3}{|c|}{$\begin{array}{l}\text { Frequency of the mu- } \\
\text { cosal wave }\end{array}$} \\
\hline Normal & 2 & 8.7 \\
\hline Decreased & 21 & 91.3 \\
\hline \multicolumn{3}{|l|}{ Symmetry } \\
\hline Asymmetrical & 14 & 60.9 \\
\hline Symmetrical & 9 & 39.1 \\
\hline \multicolumn{3}{|l|}{ Adduction posture } \\
\hline Isometric & 12 & 52.2 \\
\hline Non-isometric & 11 & 47.8 \\
\hline \multicolumn{3}{|l|}{ Periodicity } \\
\hline Consistent & 14 & 60.9 \\
\hline Diverse & 9 & 39.1 \\
\hline
\end{tabular}

Table 4: Fungal identification results in studied patients

\begin{tabular}{lcc}
\hline Characteristics & $\begin{array}{c}\text { Number of } \\
\text { patients } \\
(\mathbf{n}=\mathbf{4 8})\end{array}$ & $\begin{array}{c}\text { Percentage } \\
(\%)\end{array}$ \\
Fungal identification & 28 & 58.3 \\
Non-positive & 20 & 41.7 \\
Positive & & \\
Type of fungus & 18 & 90.0 \\
Aspergillus fumigatus & 2 & 10.0 \\
Candida albicans & & \\
\hline
\end{tabular}

worsened or other symptoms started to develop. This process usually lasted more than 3 months (or longer) before hospital admission. In our study, 29.2\% patients developed aphonia, which was the most severe consequence of dysphonia. Our study shared similar results with previous studies ${ }^{5,6}$.

Among our samples, the pseudo-membrane seen on endoscopic imaging could differ but it was more likely to be growing as a thick layer than as a thin, patchy layer. Of note, $100 \%$ of our patients had fungal pseudo-membrane on their vocal cords which could explain why all patients had dysphonia. Our result were similar to prior studies, with a $100 \%$ chance of finding fungal pseudo-membrane on the true vocal folds ${ }^{5,6}$. Most of our patients had inflammation in tissue layer under the pseudo-membrane, which might be a response of the body to the spread of the fungal pseudo-membrane. Only one-fifth of patients developed shallow ulceration, which was in line with a previous study ${ }^{1,5}$; however, the authors of that study found necrotic tissues in $28 \%$ of the patients, whereas we did not record any case of necrotic tissue layer under the biofilm.

Stroboscopic imaging informed clear, detailed images of complete movement of the vocal cords in phonation which endoscopic images were unable to provide. In this study, although the pseudo-membrane occurred on both sides of the vocal cord, we did not record any restricted movement or stiffness in the vocal cord. Meanwhile, most of the patients suffered loss of mucosal wave formation. Indeed, the mucosal wave was dependent on the structure of the vocal cord. Because most patients had vocal cord covered by a thick layer of pseudo-membrane, the fungal pseudo-membrane could alter the vocal cord structure, causing abnormalities such as complete loss of the mucosal wave. Our results indicate that while the 
pseudo-membrane restricted some physical movements of the vocal cords, the basic physiology of the vocal cords was not likely to be affected. The fungal pseudo-membrane covered some parts of the vocal cords, disrupting the normal anatomy and physiology of phonation in the vocal cords and disabling the vocal cords to close completely at the end of the phase. Only two-fifth of our patients had a positive result of fungal identification. Others had negative results, or they were unable to even perform the test. One reason was the insufficient amount of pseudo-membrane for specimen extraction. At the National Ear-NoseThroat Hospital, our first choice of laboratory test for diagnosis was direct microscopy. However, the direct microscopy merely returned positive or negative results; thus, our treatment had not specifically targeted the pathogenic fungus. The test results were similar to other studies previously conducted in Vietnam, with Aspergillus being the superior species for fungal laryngitis, ranging from $66.33 \%$ to over $90.3 \%{ }^{5,6}$. Aspergillus fumigatus and Candida albicans were the only species found within its genus in our study samples. Aspergillus fumigatus was an opportunistic airborne pathogen. In recent years, global warming and high pollution, especially in bigger cities of Vietnam, have created an ideal environment for Aspergillus to survive and reproduce, forming airborne spores.

This study had several limitations. Firstly, this study was conducted in a shorter period with a small sample size. Secondly, we did not collect data on the history of drugs and medicine related to fungal laryngitis, such as corticoids and antibiotics. Finally, at the beginning of the study, because of the shortcomings in the fungal pseudo-membrane specimen extraction and preservation technique, a few fungal identification results were negative and were excluded from the study.

\section{CONCLUSION}

Patients with fungal laryngitis in our setting developed prolonged dysphonia. By using endoscopic imaging and stroboscopic imaging, layers of fungal pseudo-membrane on the vocal cords could be observed and extracted for diagnosis. A better understanding of the clinical presentations of fungal laryngitis will improve the accuracy of diagnosis and potentially shorten treatment duration.

\section{ABBREVIATIONS}

Not applicable.

\section{ACKNOWLEDGMENTS}

The authors are thankful to the Endoscopy Department of the National Ear-Nose-Throat Hospital of
Vietnam for providing the administrative support to do this study.

\section{AUTHOR'S CONTRIBUTIONS}

Pham Thi Linh Trang: Conceptualization, Investigation, Project administration, Formal analysis, Software, Methodology, Visualization, Writing - original draft, Writing - review \& editing. Dao Dinh Thi: Conceptualization, Investigation, Methodology, Validation, Visualization, Writing - original draft, Writing - review \& editing. Nguyen Tuan Son: Conceptualization, Supervision, Validation, Visualization, Writing - original draft, Writing - review \& editing. All authors read and approved the final manuscript.

\section{FUNDING}

Not applicable.

\section{AVAILABILITY OF DATA AND MATERIALS}

Data and materials used and/or analyzed during the current study are available from the corresponding author on reasonable request.

\section{ETHICS APPROVAL AND CONSENT TO PARTICIPATE}

This study was conducted in accordance with the amended Declaration of Helsinki. The institutional review board (The Institutional Review Board of the School of Medicine and Pharmacy, Vietnam National University, Hanoi) approved the study, and all participants provided written informed consent.

\section{CONSENT FOR PUBLICATION}

Not applicable.

\section{COMPETING INTERESTS}

The authors declare that they have no competing interests.

\section{REFERENCES}

1. Brown GD, Denning DW, Gow NA, Levitz SM, Netea MG, White TC. Hidden killers: human fungal infections. Science translational medicine. 2012;4(165):165rv13. PMID: 23253612. Available from: https://doi.org/10.1126/scitranslmed.3004404.

2. Pal M. Veterinary and medical mycology eds, editor. New Delhi, India: Indian Council of Agricultural Research. 2007.

3. Guinea J, Torres-Narbona M, Gijon P, Munoz P, Pozo F, Pelaez T, et al. Pulmonary aspergillosis in patients with chronic obstructive pulmonary disease: incidence, risk factors, and outcome. Clinical microbiology and infection : the official publication of the European Society of Clinical Microbiology and Infectious Diseases. 2010;16(7):870-877. PMID: 19906275. Available from: https://doi.org/10.1111/j.1469-0691.2009.03015.x. 
4. Wood JM, Athanasiadis T, Allen J. Laryngitis. BMJ. 2014;349:g5827. PMID: 25300640. Available from: https://doi.org/10.1136/bmj.g5827.

5. Huong L. Research on diagnosis and treatment of fungal laryngitis. Ha Noi; 2004.

6. Dung T, Nguyen D. Diagnosis and treatment of fungal laryngitis.
Ho Chi Minh City Medical Journal. 2011;15(1):222-227.

7. Ravikumar A, Prasanna Kumar S, Somu L, Sudhir B. Fungal laryngitis in immunocompetent patients. Indian J Otolaryngol Head Neck Surg. 2014;66(1):375-378. PMID: 24533421. Available from: https://doi.org/10.1007/s12070-011-0322-7. 